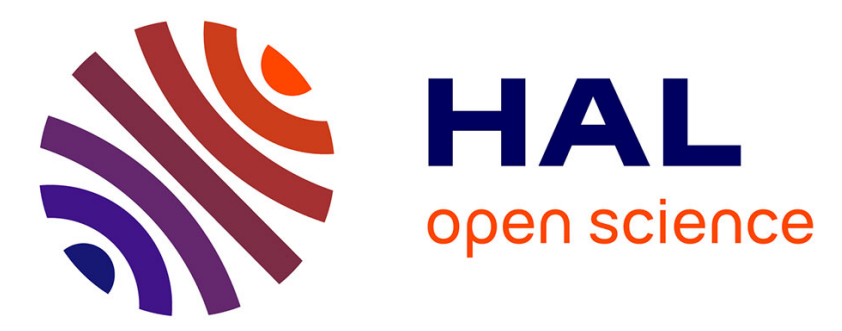

\title{
Cognitive tasks modelization and description in VR environment for Alzheimer's disease state identification
}

Florian Maronnat, Margaux Seguin, Khalifa Djemal

\section{To cite this version:}

Florian Maronnat, Margaux Seguin, Khalifa Djemal. Cognitive tasks modelization and description in VR environment for Alzheimer's disease state identification. 10th International Conference on Image Processing Theory, Tools and Applications (IPTA 2020), Nov 2020, Paris, France. pp.1-7, 10.1109/IPTA50016.2020.9286627 . hal-03404812

\section{HAL Id: hal-03404812 \\ https://hal.science/hal-03404812}

Submitted on 26 Oct 2021

HAL is a multi-disciplinary open access archive for the deposit and dissemination of scientific research documents, whether they are published or not. The documents may come from teaching and research institutions in France or abroad, or from public or private research centers.
L'archive ouverte pluridisciplinaire $\mathbf{H A L}$, est destinée au dépôt et à la diffusion de documents scientifiques de niveau recherche, publiés ou non, émanant des établissements d'enseignement et de recherche français ou étrangers, des laboratoires publics ou privés. 


\section{Cognitive tasks modelization and description in VR environment for Alzheimer's disease state identification}

\author{
MARONNAT Florian \\ IBISC Laboratory \\ Paris Saclay University \\ Evry, France \\ Florian.maronnat@univ-evry.fr
}

\author{
SEGUIN Margaux \\ IBISC Laboratory \\ Paris Saclay University \\ Evry, France \\ Margaux.Seguin@ensiie.fr
}

\author{
DJEMAL Khalifa \\ IBISC Laboratory \\ Paris Saclay University \\ Evry, France \\ Khalifa.Djemal@univ-evry.fr
}

\begin{abstract}
With more than 132 million of patients estimated in 2050, Alzheimer's disease is a worldwide public health problem with no current treatment. Its diagnosis especially consists into realizing paper assessments exploring the different fields of cognition. Virtual reality has become an essential tool in informatic and in medical practice. Due to their lack of immersion, paper tests are not ecological and so virtual reality appears to be more ecological. We aimed to create virtual cognitive tasks in an immersive environment. These tasks were inspired from usual tests such à Mini Mental Examination Status or Montréal Cognitive Assessment. Thirteen scenes with different models were edited and uploaded in the Oculus Quest. Multiple cognitive functions were tested such as orientation, attention, memory or praxis. The system let an easy and autonomous utilization with an avatar. Our issue is now to test it on a healthy population and in AD patients to validate its validity and reliability.
\end{abstract}

Keywords: Alzheimer disease, Virtual reality, cognitive assessment, dementia

\section{INTRODUCTION}

Alzheimer's disease (AD) is the first cause of neurodegenerative dementia leading to a major cognitive decline and loss of a autonomy [1]. The current prevalence is about 47 millions of patients worldwide with an expectation of 132 million patients in 2050 representing a total cost of 2000 billions of dollars [1]. Thus, it represents a huge public health problem either on diagnostic or therapeutics.

Diagnosis is based on clinical symptoms such as memory loss, biological measures of biomarkers (tau and beta - amyloid proteins) [2] or radiological abnormalities (hippocampal atrophy) [3].

There is currently no curative available treatment.

In $\mathrm{AD}$ two stages are described: Mild Cognitive Impairment (MCI) and dementia stage. MCI corresponds to a cognitive decline with no loss of autonomy whereas dementia occurs when a loss of autonomy appears [4].

Severity can be measured by two scales: Global Deterioration Scale (GDS) published in 1982 with 7 stages of severity [5] and Clinical Dementia Rating (CDR) published in 1984 with 3 stages [6]. Both use algorithms including cognitive and autonomy measures.

Exploring cognitive decline relies on multiple tests' realisation. Numerous tests have been developed either for general evaluation or specific exploration of a cognitive function.

The most cited and used test is the Mini - Mental Status Examination (MMSE) published in 1975 by Folstein [7]. Composed of 30 questions it explores different fields of cognition such as orientation, praxis or language and is so a general test.
More recently, The Montréal Cognitive Assessment (MoCA) was published in 2005 [8]. Originally in French language it has been translated into English and is now more and more used with or in replacement of the MMSE. It lets a better exploration of frontal functions than the MMSE.

Ciesielska and al demonstrated that the MoCA had a higher sensitivity (Se) than the MMSE to differentiate healthy subjects from MCI patients although MMSE still has a higher specificity (Sp) [9]. Good correlations were also found between the two tests reaching 0,633 [10] to 0,76 [11].

Another test used in detection of AD is The five words of Dubois (F5D) [12]. The patient needs to remember 5 words with a first free and indexed recall and a second one after an interfering task. Its sensitivity and specificity reach 0,91 and 0,87 respectively.

Virtual reality (VR) has become in a few years an essential tool in informatics and video games but also in medical practice such as surgery, neurology or psychiatrics $[13,14]$. Providing an immersive environment, VR offers the possibility to interact and realise actions that can be measured and scored. Improvement of image's resolutions let to create more and more immersive environments. Thereby many authors have evaluated the possibility of using VR in cognitive assessment [15].

Contrary to usual paper tests, VR is an ecological tool and so seems to be more efficient to detect cognitive decline throughout real situations [16].

With a constant increasing prevalence of and $\mathrm{AD}$, physicians need to get new tools to evaluate cognitive functions and VR appears to be an interesting and innovative one. To achieve a reliable evaluation, virtual environments must be easily available and understandable for patients. Cognitive tasks must be reproduced based on usual tests. Moreover, each action shall be weighted by a score depending on success or fail to the task. A final global score is necessary to appreciate the functioning of cognition and classify patients within healthy cognition stage or dementia.

We aim to create an immersive virtual environment with multiple tasks based on those existing in paper tests.

\section{METHODS}

\section{A. Review of literature}

Several authors have developed their own virtual environments in order to evaluate cognitive functions.

VR can be either non - immersive, half - immersive or immersive.

The least immersive VR was used on numerical tablets. Closer from a computer or a simple screen, this kind of VR offers a low degree of immersion. In 2015, Zygouris and al studied a virtual supermarket within a population of healthy and MCI subjects [17]. Global scores on virtual test were weakly 
correlated with usual tests (such as MMSE). MMSE had an accuracy of 0,67 $(\mathrm{Se}=067 ; \mathrm{Sp}=0,67)$ while under - scores of the virtual test reached an accuracy of $0,87(\mathrm{Se}=0,82 ; \mathrm{Sp}$ $=0,95)$. Later, Tong and al also used numerical tablets among elderly inpatients in an emergency department. Patients were both tested within the virtual environment and with usual tests (MMSE, MoCA) [18]. A significant relationship was found between reaction time to the test and global scores of usual tests (MMSE and MoCA)

Half - immersive VR uses new techniques such as 3D to increase immersion into the environment. Widely spread out in TV and cinema, it is also used in cognitive assessment. In 2019, Chua and al, using a TV and leap motion evaluated 70 patients with MoCA, MMSE and the virtual environment (7 tasks) [11]. Patients were either healthy or cognitively impaired. MMSE and MoCA were correlated $(p<0,02)$ to the virtual test. Moreover, MMSE and MoCA were themselves correlated $(r=0,76 ; \mathrm{P}<0,001)$

At last immersive VR allows a total visual immersion as in real environment. Other functions can be added to increase immersion such as interaction functions (moving objects e.g). In 2013, Nolin and al. created an environment with glasses and helmet [19]. Healthy and MCI subjects were both tested with MoCA and virtual test. MoCA shew a significant relationship with the virtual test $(\mathrm{r}=0,45 ; \mathrm{p}<0,01)$. More recently Fernandez Montenegro and al test an immersive environment on healthy and AD subjects. Patients underwent 4 classic tests and 4 virtual tests (including Turing test). All the virtual test (excepting Turing test) had a significant correlation $(\mathrm{p}<0,05)$ with classical ones.

Regarding the few studies presented, we can note that virtual tests are efficient to evaluate cognitive functions. Most of them presented strong correlations with classical tests justifying their further development. Furthermore, authors widely chose to evaluate their patients with the two major tests MMSE and MoCA.

Thereby we chose to develop an immersive environment with cognitive tasked inspired on those present in three major tests: MMSE, MoCA et and the five words of Dubois (F5B).

\section{B. Cognitive tasks}

Aiming to browse many fields of cognition as possible, we decided to virtualize all the following tasks presented in Table 1.

\section{Machine learning model}

One of the objectives of our project is the creation of a learning model with the help of machine learning (ML). This model would be able to detect and classify the cognitive status of a new patient realising all the virtual tasks.

Each score at a virtual task becomes a weighted vector. We based the virtual scores on those present in original tests $[7,8,12]$. The maximum scores for each virtual task are presented in Table 2.

The total score is represented by the sum of the 13 vectors which are natural whole numbers (Fig 1).

\begin{tabular}{|c|c|c|c|c|}
\hline \multirow{2}{*}{$\begin{array}{l}\text { Cognitive } \\
\text { domain }\end{array}$} & \multirow{2}{*}{ Task } & \multicolumn{3}{|c|}{ Test } \\
\hline & & MMSE & MoCA & $F 5 D$ \\
\hline Orientation & $\begin{array}{c}\text { Spatial and } \\
\text { Temporal }\end{array}$ & $x$ & $x$ & \\
\hline \multirow{3}{*}{ Attention } & Calculation & $x$ & $x$ & \\
\hline & List of letters & & $x$ & \\
\hline & Number series & & $x$ & \\
\hline Memory & $\begin{array}{l}\text { Five words with } \\
\text { immediate and } \\
\text { delayed recall }\end{array}$ & & & $x$ \\
\hline \multirow{3}{*}{$\begin{array}{l}\text { Executive } \\
\text { and } \\
\text { visuospatial } \\
\text { functions }\end{array}$} & $\begin{array}{l}\text { Drawing } \\
\text { (constructive } \\
\text { praxis) }\end{array}$ & $x$ & $x$ & \\
\hline & $\begin{array}{c}\text { Logical } \\
\text { Sequence }\end{array}$ & & $x$ & \\
\hline & Clock & & $x$ & \\
\hline Praxis & $\begin{array}{l}\text { Sequence of } \\
\text { movements }\end{array}$ & $x$ & & \\
\hline \multirow{2}{*}{ Language } & Naming & $x$ & $x$ & \\
\hline & Written order & $x$ & & \\
\hline Abstraction & Associations & & $x$ & \\
\hline
\end{tabular}

Table 1: Selection of cognitive tasks in virtual environment

\begin{tabular}{|c|c|c|c|}
\hline Cognitive domain & \multicolumn{2}{|c|}{ Virtual Task } & $\begin{array}{c}\text { Maximum } \\
\text { score }\end{array}$ \\
\hline \multirow{3}{*}{ Attention } & \multicolumn{2}{|c|}{ Ball task } & 5 \\
\hline & \multicolumn{2}{|c|}{ List of letters } & 1 \\
\hline & \multicolumn{2}{|c|}{ List of words } & 1 \\
\hline Abstraction & \multicolumn{2}{|c|}{ Similarities } & 3 \\
\hline \multirow{2}{*}{ Orientation } & \multicolumn{2}{|c|}{ Spatial } & 5 \\
\hline & \multicolumn{2}{|c|}{ Temporal } & 5 \\
\hline \multirow{3}{*}{$\begin{array}{l}\text { Executive and } \\
\text { visuospatial } \\
\text { functions }\end{array}$} & \multicolumn{2}{|c|}{ Drawing } & 1 \\
\hline & \multicolumn{2}{|c|}{ Logical Sequence } & 1 \\
\hline & \multicolumn{2}{|c|}{ Clock test } & 3 \\
\hline \multirow{2}{*}{ Memory } & \multirow{2}{*}{$\begin{array}{c}\text { Five } \\
\text { Words }\end{array}$} & $1^{\text {st }}$ recall & 5 \\
\hline & & $2^{\text {nd }}$ recall & 5 \\
\hline \multirow{2}{*}{ Language } & \multicolumn{2}{|c|}{ Naming } & 3 \\
\hline & \multicolumn{2}{|c|}{ Written order } & 2 \\
\hline Total & \multicolumn{2}{|c|}{$\mathrm{N}=13$} & 40 \\
\hline
\end{tabular}

Table 2: Maximum scores on virtual tasks

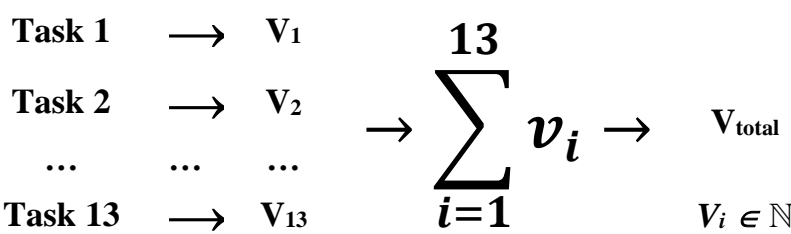

Figure 1: Creation of vectors of machine learning model from every virtual feature 


\section{Materials}

All the scenes were designed with Unity® and Visual Studio ${ }^{\circledR}$ software.

Considering that the program would be destinated for patients with a potential cognitive trouble, we chose to upload our scenes into an immersive helmet, the Oculus Quest (OQ)®. Due to its integrated computer, OQ allows free movements without plugs or cables.

Movements into the environment were directly controlled by camera position changing. Indeed, patients with cognitive impairment might not understand how to use a joystick to move into the scenes.

All the instructions were orally given throughout the headphones in the helmet.

For more easiness, tests were designed to be executed on a sitting position but could also be executed while standing.

\section{VIRTUAL TASKS}

Thirteen scenes were created based on Table 1.

The environment is a house in nature with multiples rooms and an outside landscape (Fig 2a \& 2b). The integrated leap motion allows the appearance of two hands increasing reality's feeling (Fig 2c).

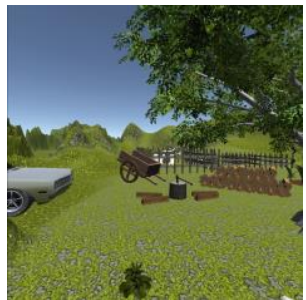

Figure 2a: View of the outdoor of the virtual environment

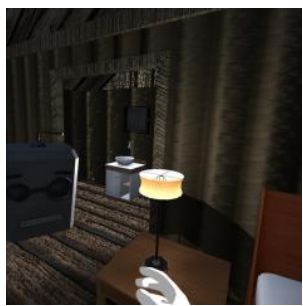

Figure 2b: View of the indoor of the virtual environment

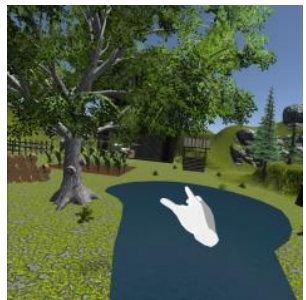

Figure 2c: Appearance of hands in virtual environment

Before beginning the tests, an introduction and a training task is presented to the patient (Fig 2d). An avatar welcomes the patient and asks the questions as a medical doctor would do. At the end of each test the avatar delivers a congratulation message to decrease stress.

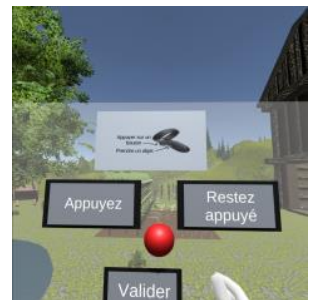

Figure 2d: Training task for using oculus quest and hand's movements

\section{A. Attention}

In MMSE and MoCA the patient must perform subtractions with a constant decreasing.

In our virtual environment the task consists in touching a ball among a line (the seventh one) (Fig 3). After touching the ball, the previous ones disappear, and the task must be renewed. As in MMSE and MoCA the patient needs to remember the order.

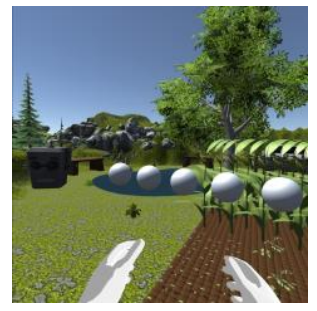

Figure 3: Attention task with ball line in outdoor environment

Another task proposed in the MoCA is a list of letters. The patient hits with its hand when it hears the specific letter. In the virtual environment the patient hears in the headphone a list of letters and must push on a button when the triggered letter is pronounced (Fig 4).

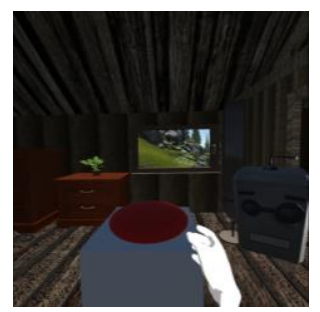

Figure 4: List of letters test. The patient must push on the red button when targeted letter is heard

For the number series present in MoCA test we decided to virtualize it as a list of words to remember (Fig 5). Firstly, the patient hears a list (square, circle, triangle) and needs to remember it. Then it will be asked to replace the figures in the right order

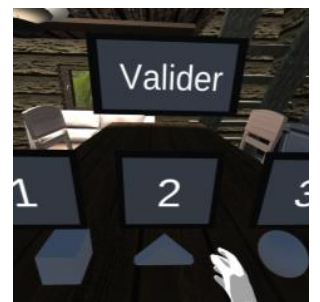

Figure 5: Order series. The patient must replace objects in the previously heard order 


\section{B. Abstraction}

In MoCA, associations are proposed as "what are the similarity between an orange and a banana?".

The virtual tasks consisted is moving objects under pictures of similar categories (vegetable, transport, object) (Fig 6).

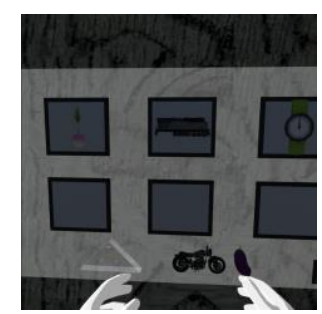

Figure 6: Abstraction task where the patient needs to place images below the similar picture

\section{Orientation}

As the MMSE and the MoCA, the virtual task explores either temporal (day, season, month, year) (Fig 7a \& 7b) and spatial orientation (place, town) (Fig 7c).

In the different scenes, patient must choose among a list.

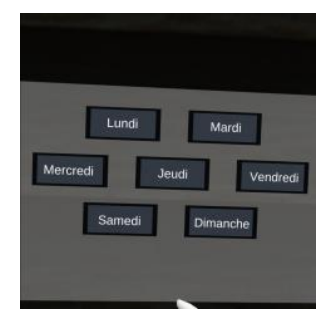

Figure 7a: List of weekdays for temporal orientation

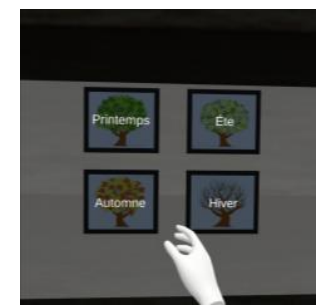

Figure 7b: List of seasons with pictures for temporal orientation

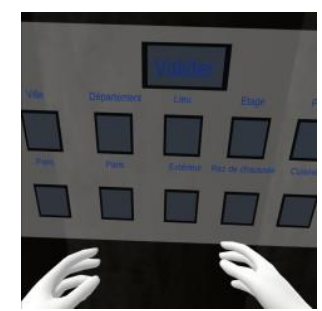

Figure 7c: List of town, department, place and floor for temporal orientation

\section{Executive and visuospatial functions}

For the drawing task (constructive praxis) two figures must be assembled to make a new one (Fig 8).

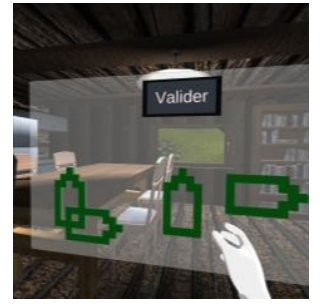

Figure 8: Drawing task with two figures to cross

As in MoCA, the virtual logical sequence is a course where the patient must link numbers and letters in a specific order (1A, 2B, 3C...) (Fig 9)

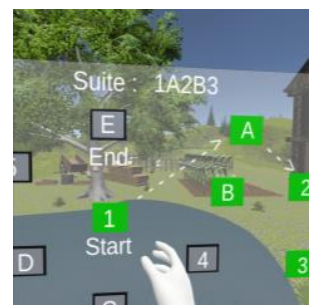

Figure 9: Logical sequence with the order to follow (number then letter)

Clock test explores the visuospatial abilities. The patient must agree if the displayed clock corresponds with the hour given (Fig 10).

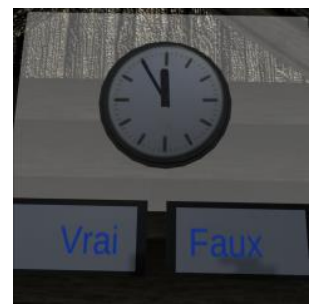

Figure 10: Clock test. The patient must agree or disagree if the heard hour corresponds to the displayed clock.

\section{E. Language}

The naming task in MoCA has been virtualized in the outdoor scenes of the environment. Three enclosures are presented to the patient with three different animals. Then the patient must choose the right name among a proposed list (Fig 11).

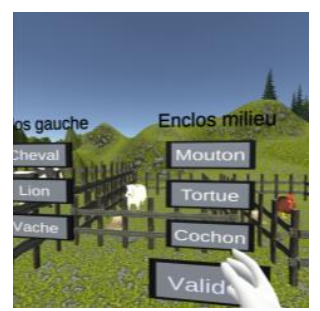

Figure 11: Naming task with the animal's enclosures and names

For the written order a sentence is displayed in the environment with an order to place figures at good place (red ball on red circle, blue ball and blue circle etc) (Fig 12). 


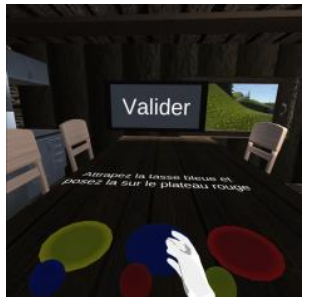

Figure 12: Written order with coloured objects and targets

\section{F. Memory}

Our virtual scene for memory exploration is based on the Five words of Dubois (Fig 13a \& 13b).

A list of five words is presented to the patient and must be remembered.

There is an immediate recall displayed presented as a list of 16 words with the initial 5 .

For those not found, an indexed question appears such as "what was the building?"

An interfering task occurs and a delayed recall (free and indexed) is then proposed.

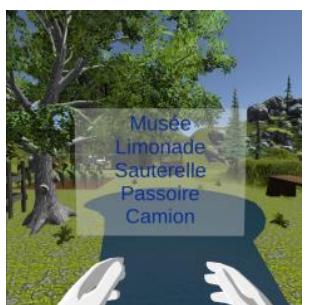

Figure 13a: List of words to remember before immediate and delayed recall

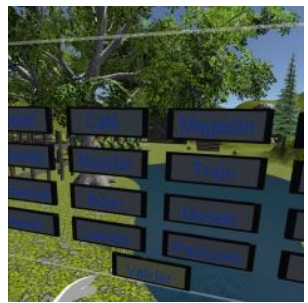

Figure 13b: List of the 16 words proposed for immediate and delayed recall

\section{DISCUSSION}

As presented in the brief review, many authors have developed virtual environments to perform cognitive assessments.

In the different studies, new environments were created with scenarios exploring several areas of cognition but never with tasks directly inspired from usual tests. MMSE and MOCA are worldwide widely used in cognitive assessment although MMSE shall be interpreted with precaution [20,21]. We therefore considered interesting to modelize tasks close from these tests in our environment and our study is the first one to base its virtual scenes on two major general tests (MMSE and MocA) and a specific one of AD (F5D).

We succeeded in modelizing most of the tasks present in the three tests. The thirteen scenes allow an assessment of language, praxis, abstraction, executives functions, orientation, attention and memory. The program is relatively complete by combining several robust tests. It improves its reliability and accuracy and leads to a better and more precise assessment.

The environment composed of a house and a garden allows a more ecological approach than usual paper tests. Modelizing these tests while increasing ecology enhances accuracy and facilitates utilisation among frail populations.

At last patients may have difficulties in understanding VR and its utilisation. This kind of immersive and familiar environment can reassure them and feel more confortable than a simple computerized test on a screen or a classic examination and the fear to fail.

Nevertheless, our project also presents limits as usual tests do.

Indeed, some tasks cannot be easily modelized to look like their presentation in classical paper tests.

Due to the wished autonomy of our program, many tasks originally oral in usual tests are now presented as text (orientation, five words, naming). One solution would be the integration of a vocal recognition program. The question would be orally given through the headphones and the patient would answer orally. However, it needs a robust software and a good pronunciation from the patient otherwise the score could be falsely impaired.

The environment doesn't evaluate writing or fluency. We tried to find an intermediate solution to assess drawing by the task of assembling two pieces to reproduce a figure. Of course, the patient doesn't draw with a pen which is the best way of assessing drawing. For both drawing and writing, it could be possible to introduce a virtual pen into the environment, but it would need the verification of an examiner instead of automatic validation. During clock test, the patient needs to write the numbers then draw the hands at the asked hour. Modelizing this task would be difficult and would also need an examiner's advice before validation. We so decided to display a clock to the patient who must agree if the displayed time is the same as the heard time in the headphones. Concerning fluency, a vocal recognition software could be useful but there would be the same limitations as cited previously.

In MMSE or MoCA, some tasks also need to know reading but our program present more reading tasks than usual tests. Recently Franzen and al have published a review about cognitive assessment in low - educated people [22]. They shew that some tests appear to be reliable for non-reading people as the Five Digit Test [23].

Most of the patients presenting cognitive troubles are old and so may have sensory loss as vision or hearing impairment. The sound can be easily increased or decreased in the headphones, but the voice needs to be clear et slow to deliver an audible message. However, vision impairment may not be compatible with a virtual assessment as macular degeneration. This is also a problem with classical tests. Nevertheless, with a higher number of questions needing reading, it increases the potential difficulties of passing the test with a vision impairment. Colours and contrasts must be carefully chosen to achieve a fluid and easy reading.

Aiming to create an autonomous system for cognitive's status evaluation and classification, we chose to add a program of ML into our virtual environment. Indeed, all models using ML in dementia as Choi and al base their analysis on classical 
paper tests [24]. Hitherto, no study was found in literature combining a virtual cognitive assessment and a machine learning model neither on Alzheimer's disease nor dementia in general. Levy and al have evaluated three models of ML (Support Vector Machine, Random Forest, and Gradient Boosting Trees) with a computerized cognitive test against MoCA [25]. Gradient Boosting Trees reached an accuracy and AUC of 0.81. Although the used test was not a virtual environment, it shows that ML combined with an informatic test is a pertinent mean to assess cognitive status.

$\mathrm{VR}$ is about to become a unique and ecological mean to assess cognitive functions. However, daily utilization is not yet widespread due to the multiple interfaces and lack of studies in large populations.

Despite technical limitations and improvements needed, our model is closer from major tests as MMSE and MoCA than other virtual environments published. We expect it could be able to evaluate and classify a patient into healthy or impaired within only 13 tasks. Of course, it will not be a tool for etiological diagnosis, but it shall be useful in the following of a cognitive trouble for example or in primary care as screening. With an increasing prevalence of $\mathrm{AD}$, we need to get simple and accessible means to achieve brief screenings. An autonomous functioning will let a large diffusion of the tool into the health care system and so a better utilization among patient with the goal to screen and detect the most possible cognitive decline. To achieve this model, we will need to get a large database of records from both healthy and cognitively impaired patients.

\section{CONCLUSION}

VR is an increasing method used in cognitive assessment showing both reliability and accuracy but without modelizing classical tests.

Aiming to build a new immersive virtual environment we decided to virtualize 13 scenes based on three classic tests (MMSE, MoCA and F5D) exploring several fields as attention, praxis or memory.

The virtual environment will be soon tested in a population of patients

This work represents an initial step for an autonomous identification system of cognitive impairment based on a machine learning model.

\section{REFERENCES}

[1] Alzheimer's Disease International n.d. https://www.alz.co.uk/ (accessed June 21, 2019).

[2] Dubois B, Feldman HH, Jacova C, Hampel H, Molinuevo JL, Blennow K, et al. Advancing research diagnostic criteria for Alzheimer's disease: the IWG-2 criteria. Lancet Neurol 2014;13:614-29. https://doi.org/10.1016/S1474-4422(14)70090-0.

[3] Haute Autorité de Santé - Maladie d'Alzheimer et maladies apparentées : diagnostic et prise en charge n.d. https://www.has-sante.fr/jcms/c_1148883/fr/maladie-dalzheimer-et-maladies-apparentees-diagnostic-et-priseen-charge (accessed February 17, 2020).

[4] American Psychiatric Association. Diagnostic and statistical manual of mental disorders, 5thed. 2013.
[5] Reisberg B, Ferris SH, de Leon MJ, Crook T. The Global Deterioration Scale for assessment of primary degenerative dementia. Am J Psychiatry 1982;139:1136-9. https://doi.org/10.1176/ajp.139.9.1136.

[6] Berg L. Clinical Dementia Rating. Br J Psychiatry J Ment Sci 1984;145:339.

[7] Folstein MF, Folstein SE, McHugh PR. "Mini-mental state". A practical method for grading the cognitive state of patients for the clinician. J Psychiatr Res 1975;12:189-98.

[8] Nasreddine ZS, Phillips NA, Bédirian V, Charbonneau S, Whitehead V, Collin I, et al. The Montreal Cognitive Assessment, MoCA: a brief screening tool for mild cognitive impairment. J Am Geriatr Soc 2005;53:695-9. https://doi.org/10.1111/j.1532-5415.2005.53221.x.

[9] Ciesielska N, Sokołowski R, Mazur E, Podhorecka M, Polak-Szabela A, Kędziora-Kornatowska K. Is the Montreal Cognitive Assessment (MoCA) test better suited than the Mini-Mental State Examination (MMSE) in mild cognitive impairment (MCI) detection among people aged over 60? Meta-analysis. Psychiatr Pol 2016;50:1039-52. https://doi.org/10.12740/PP/45368.

[10] Bergeron D, Flynn K, Verret L, Poulin S, Bouchard RW, Bocti $\mathrm{C}$, et al. Multicenter Validation of an MMSEMoCA Conversion Table. J Am Geriatr Soc 2017;65:1067-72. https://doi.org/10.1111/jgs.14779.

[11] Chua SIL, Tan NC, Wong WT, Allen JC, Quah JHM, Malhotra R, et al. Virtual Reality for Screening of Cognitive Function in Older Persons: Comparative Study. J Med Internet Res 2019;21:e14821. https://doi.org/10.2196/14821.

[12] Dubois B, Touchon J, Portet F, Ousset PJ, Vellas B, Michel B. ["The 5 words": a simple and sensitive test for the diagnosis of Alzheimer's disease]. Presse Medicale Paris Fr 1983 2002;31:1696-9.

[13] Tarnanas I, Schlee W, Tsolaki M, Müri R, Mosimann U, Nef T. Ecological validity of virtual reality daily living activities screening for early dementia: longitudinal study. JMIR Serious Games 2013;1:e1. https://doi.org/10.2196/games.2778.

[14] Liu Y, Tan W, Chen C, Liu C, Yang J, Zhang Y. A Review of the Application of Virtual Reality Technology in the Diagnosis and Treatment of Cognitive Impairment. Front Aging Neurosci 2019;11:280. https://doi.org/10.3389/fnagi.2019.00280.

[15] García-Betances RI, Arredondo Waldmeyer MT, Fico G, Cabrera-Umpiérrez MF. A succinct overview of virtual reality technology use in Alzheimer's disease. Front Aging Neurosci 2015;7:80. https://doi.org/10.3389/fnagi.2015.00080.

[16] Parsons TD. Virtual Reality for Enhanced Ecological Validity and Experimental Control in the Clinical, Affective and Social Neurosciences. Front Hum Neurosci 2015;9:660. https://doi.org/10.3389/fnhum.2015.00660.

[17] Zygouris S, Giakoumis D, Votis K, Doumpoulakis S, Ntovas K, Segkouli S, et al. Can a virtual reality cognitive training application fulfill a dual role? Using the virtual supermarket cognitive training application as a screening tool for mild cognitive impairment. J 
Alzheimers Dis JAD 2015;44:1333-47. https://doi.org/10.3233/JAD-141260.

[18] Tong T, Chignell M, Tierney MC, Lee J. A Serious Game for Clinical Assessment of Cognitive Status: Validation Study. JMIR Serious Games 2016;4:e7. https://doi.org/10.2196/games.5006.

[19] Nolin P, Banville F, Cloutier J, Allain P. Virtual Reality as a New Approach to Assess Cognitive Decline in the Elderly. Acad J Interdiscip Stud 2013;2:612.

[20] Trivedi D. Cochrane Review Summary: Mini-Mental State Examination (MMSE) for the detection of dementia in clinically unevaluated people aged 65 and over in community and primary care populations. Prim Health Care Res Dev 2017;18:527-8. https://doi.org/10.1017/S1463423617000202.

[21] Arevalo-Rodriguez I, Smailagic N, Roqué I Figuls M, Ciapponi A, Sanchez-Perez E, Giannakou A, et al. MiniMental State Examination (MMSE) for the detection of Alzheimer's disease and other dementias in people with mild cognitive impairment (MCI). Cochrane Database Syst Rev 2015:CD010783. https://doi.org/10.1002/14651858.CD010783.pub2.
[22] Franzen S, van den Berg E, Goudsmit M, Jurgens CK, van de Wiel L, Kalkisim Y, et al. A Systematic Review of Neuropsychological Tests for the Assessment of Dementia in Non-Western, Low-Educated or Illiterate Populations. J Int Neuropsychol Soc 2020;26:331-51. https://doi.org/10.1017/S1355617719000894.

[23] Sedó MA. ['5 digit test': a multilinguistic non-reading alternative to the Stroop test]. Rev Neurol 2004;38:8248.

[24] Choi H-S, Choe JY, Kim H, Han JW, Chi YK, Kim K, et al. Deep learning based low-cost high-accuracy diagnostic framework for dementia using comprehensive neuropsychological assessment profiles. BMC Geriatr 2018;18:234. https://doi.org/10.1186/s12877-018-0915-z.

[25] Levy B, Hess C, Hogan J, Hogan M, Ellison JM, Greenspan S, et al. Machine Learning Enhances the Efficiency of Cognitive Screenings for Primary Care. J Geriatr Psychiatry Neurol 2019;32:137-44. https://doi.org/10.1177/0891988719834349. 